\title{
HUBUNGAN PENGETAHUAN DAN SIKAP DOKTER DENGAN KESESUIAN KODING DIAGNOSIS BERDASARKAN ICD-10 DI RSUD ARJAWINANGUN CIREBON
}

\author{
RELATIONSHIP OF KNOWLEDGE AND ATTITUDE OF \\ DOCTORS WITH ADJUSTMENT OF CODING \\ DIAGNOSIS BASED ON ICD-10 \\ IN RSUD ARJAWINANGUN CIREBON
}

\author{
Andi Suhenda ${ }^{1}$, Bambang Karmanto ${ }^{2}$, Suhartini ${ }^{3}$ \\ 1,2,3Poltekkes Kemenkes Tasikmalaya Jawa Barat \\ Email : andisuhenda@gmail.com, bambangkarmanto@gmail.com, \\ atinahmad99@gmail.com
}

\begin{abstract}
ABSTRAK
Rekam medis yang tidak diisi dengan tepat dan lengkap akan mengakibatkan informasi yang dihasilkan menjadi tidak akurat. Diagnosis harus sesuai dengan ICD-10 agar proses pengkodingan menjadi lebih mudah dan menghasilkan kode diagnosis yang tepat dan akurat.Tujuan umum penelitian adalah untuk mengetahui hubungan antara pengetahuan dan sikap dokter tentang rekam medis dengan ketepatan koding diagnosis berdasarkan ICD10 di Unit Rawat Jalan RSUD Arjawinangun Kabupaten Cirebon. Jenis penelitian adalah kuantitatif dengan rancangan crosssectional. Populasi dalam penelitian seluruh dokter spesialis sebanyak 34 orang dan dokumen rekam medis Rawat Jalan sebanyak 1200 dokumen. Sampling pada dokter menggunakan teknik total sampling dan pada dokumen rekam medis menggunakan teknik accidental sampling. instrumen peneltian adalah kuesioner dan checklist. Uji hipotesis menggunakan uji Chi-square.Pengetahuan responden tentang rekam medis tinggi $(61,8 \%)$, dan sikap responden tentang rekam medis baik dan kurang baik sama (50\%). Ketepatan koding diagnosis berdasarkan ICD sebanyak 1067 dokumen rekam medis $(88,9 \%)$.Ketidaktepatan koding diagnose berdasarkan ICD sebanyak 19 dokter $(55,9 \%)$ dari 34 dokter. Pengetahuan dengan ketepatan koding diagnosis berdasarkan ICD tidak berhubungan secara signifikan dengan $p$ value $=0,601$ dan nilai RP $=1$. Sikap dengan ketepatan koding diagnosis berdasarkan ICD tidak berhubungan secara signifikan dengan $p$ value $=0,084$ dan nilai $R P=0,18$. Tidak ada hubungan yang signifikan antara pengetahuan dan sikap dokter tentang rekam medis dengan kesesuaian koding diagnosis berdasarkan ICD-10 di RSUD Arjawinangun Kabupaten Cirebon. Peneliti lain selanjutnya, agar memperhatikan faktor-faktor lain yang dapat mempengaruhi ketepatankoding diagnosis.
\end{abstract}

\section{Kata Kunci : kesesuaian koding diagnosis, pengetahuan dokter, sikap dokter}

\section{ABSTRACT}

The medical record that is not filled in correctly and completely will result in the information generated being inaccurate. Diagnosis must be in accordance with ICD-10 in order to make the coding process easier and produce precise and accurate diagnostic codes. The general objective of the study was to determine the relationship between the knowledge and attitudes of doctors about medical records with the accuracy of diagnosis coding based on ICD-10 in the Outpatient Unit of Arjawinangun Hospital, Cirebon Regency. This type of research is quantitative with cross sectional design. The population in the study were all specialist doctors as many as 34 people and outpatient medical record documents as many as 1200 
documents. Sampling to doctors using total sampling technique and medical record documents using accidental sampling technique. the research instruments were a questionnaire and a checklist. Hypothesis testing using the Chi-square test. Results shows that respondents 'knowledge of medical records was high (61.8\%), and respondents' attitudes about good and poor medical records were the same $(50 \%)$. The accuracy of diagnosis coding based on ICD was 1067 medical record documents (88.9\%). Inaccuracy of diagnosis coding based on ICD was 19 doctors (55.9\%) of 34 doctors. Knowledge with the accuracy of diagnosis coding based on ICD was not significantly related to $p$ value $=0.601$ and the value of RP $=1$. Attitude with the accuracy of diagnosis coding based on ICD was not significantly associated with $p$ value $=0.084$ and $R P$ value $=0.18$. There is no significant relationship between the knowledge and attitudes of doctors about medical records with the suitability of the diagnosis coding based on ICD-10 at Arjawinangun Hospital, Cirebon Regency. Other researchers then pay attention to other factors that can affect the accuracy of the diagnosis coding.

\section{Keywords: doctor's attitude, doctor's knowledge, suitability of diagnosis coding}

\section{PENDAHULUAN}

Rekam medis adalah berkas yang berisikan catatan dan dokumen tentang identitas pasien, pemeriksaan, pengobatan, tindakan dan pelayanan yang telah diberikan kepada pasien. Pemanfaatan rekam medis dapat dipakai sebagai pemeliharaan kesehatan dan pengobatan pasien, alat bukti dalam proses penegakan hukum, disiplin kedokteran dan kedokteran gigi dan penegakkan etika kedokteran dan etika kedokteran gigi, keperluan pendidikan dan penelitian, dasar pembayar biaya pelayanan kesehatan, serta data statistik Kesehatan.

Agar dapat mencapai pemanfaatan yang optimal maka pengisian rekam medis harus diisi dengan tepat dan lengkap. Kelengkapan data rekam medis sangat tergantung pada dokter sebagai penentu sekaligus pencatat diagnosis. Rekam medis yang tidak diisi dengan tepat dan lengkap akan mengakibatkan informasi yang dihasilkan menjadi tidak akurat karena ketidaksinambungan antara hasil pendokumentasian di rekam medis dengan keadaan pasien sesungguhnya.

Diagnosis merupakan salah satu unsur penting dalam rekam medis, karena selain sebagai hasil penggambaran kondisi pasien setelah dilaksanakannya pemeriksaan oleh dokter juga sebagai penentu tindakan atau pelayanan yang akan diberikan kepada pasien. Selain itu diagnosis yang terdapat dalam rekam medis akan melalui proses pengkodingan untuk selanjutnya dilaporkan ke Dinas Kesehatan Kota/Kabupaten dalam bentuk 10 besar penyakit baik di rawat jalan maupun rawat inap. Pengkodingan dilakukan bertujuan untuk mengklasifikasikan penyakit sejenis dengan berpedoman ICD-10. Oleh karena itu pencantuman diagnosis harus sesuai dengan ICD-10 agar proses pengkodingan menjadi lebih mudah dan menghasilkan kode diagnosis yang tepat dan akurat.

Dalam pelaksanaannya tidak sedikit ditemukan pencantuman diagnosis pada rekam medis tidak sesuai dengan ICD-10, contohnya seperti pencantuman diagnosis yang tidak spesifik sehingga mengakibatkan koding yang dihasilkan menjadi tidak spesifik pula. Penelitian Maiga, et all. (2014) menunjukkan bahwa rendahnya ketepatan pengisian ICD-10 oleh dokter disebabkan lemahnya pengetahuan dan sikap dokter yang juga rendah tentang arti penting ketepatan pengisian ICD-10. Ketidaksesuaian pengisian ICD-10 pada kajian ini meliputi diagnosis tidak dituliskan, penulisan yang tidak sesuai karena dituliskan dalam bentuk singkatan, atau menggunakan terminologi yang berbeda. Kendala yang biasanya ditemukan selama mengkode diagnosis diantaranya diagnosis utama 
tidak ditulis, tulisan dokter yang sulit dibaca, penggunaan singkatan dan istilah baru.

\section{METODE}

Jenis penelitian yang digunakan adalah kuantitatif dengan rancangan crosssectional. Populasi dalam penelitian ini adalah seluruh dokter spesialis yang bekerja di RSUD Arjawinangun Kabupaten Cirebon sebanyak 34 orang dan dokumen rekam medis Rawat Jalan pertanggal 1-5 dan 10-11 Oktober 2016 sebanyak 1200 dokumen rekam medis.

Adapun teknik pengambilan sampel pada dokter menggunakan teknik total sampling dan pada dokumen rekam medis menggunakan teknik accidental sampling. Instrumen dalam peneltian ini adalah kuesioner dan checklist analisis ketepatan diagnosis pada rekam medis.

Prosedur pengumpulan data pada penelitian ini menggunakan metode pengisian kuesioner atau angket oleh responden. Selain itu, prosedur pengumpulan data juga dilengkapi dengan observasi terhadap dokumen rekam medis khususnya bagian pengisian diagnosis pada resume medis. Uji hipotesis menggunakan uji Chi-square. Uji Chisquare dipilih untuk menilai apakah ada hubungan antara variabel bebas dan terikat. Hubungan dianggap bermakna bila $p<0,05$.

\section{HASIL}

\section{Analisis univariat}

Analisis univariabel dilakukan untuk melihat deskripsi dari masing-masing variabel. Gambaran hasil penelitian masing-masing variabel pengetahuan, sikap dan ketepatan koding diagnosis berdasarkan ICD :

\section{Tabel 1. Distribusi frekuensi pengetahuan dan sikap dokter}

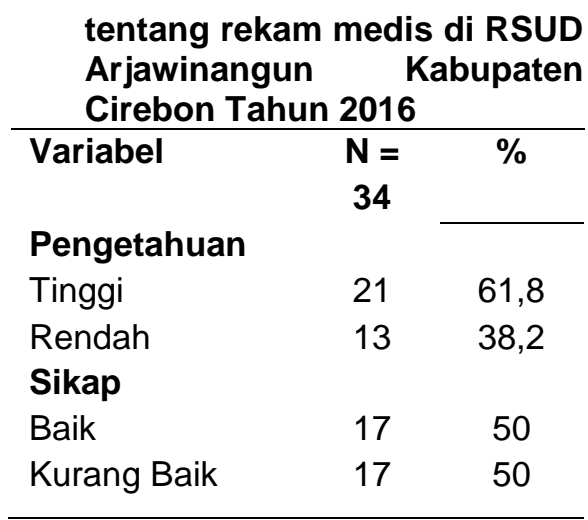

Tabel 1 menunjukkan bahwa sebagian besar pengetahuan responden tentang rekam medis tinggi $(61,8 \%)$, dan sikap responden tentang rekam medis baik dan kurang baik sama (50\%).

Tabel 2. Distribusi frekuensi ketepatan koding diagnosis berdasarkan ICD di RSUD Arjawinangun Kabupaten Cirebon Tahun 2016

\begin{tabular}{lcc}
\hline Variabel & $\mathbf{N}=$ & $\%$ \\
& 1200 & \\
\hline
\end{tabular}

Ketepatan
Koding

$\begin{array}{lcc}\text { Tepat } & 1067 & 88,9 \\ \text { Tidak Tepat } & 133 & 11,1\end{array}$

Tabel 2 menunjukkan bahwa sebagian besar ketepatan koding diagnosis berdasarkan ICD tepat yaitu sebanyak 1067 dokumen rekam medis $(88,9 \%)$.

\section{Analisis bivariat}

Hasil analisis variabel dokter dengan variabel ketepatan kode diagnostik berdasarkan ICD dapat dilihat pada tabel 3 :

Tabel 3. Distribusi antara dokter dengan ketepatan koding diagnosis berdasarkan ICD di RSUD Arjawinangun Kabupaten Cirebon Tahun 2016

\begin{tabular}{lcc}
\hline & \multicolumn{2}{c}{ Ketepatan } \\
\cline { 2 - 3 } & Tepat & $\begin{array}{c}\text { Tidak } \\
\text { Tepat }\end{array}$ \\
\hline Dokter & 15 & 19 \\
& $(44,1 \%)$ & $(55,9 \%)$ \\
\hline
\end{tabular}

Pada tabel 3 didapat bahwa ketepatan koding diagnosa berdasarkan ICD di 
RSUD Arjawinangun Kabupaten Cirebon sebanyak 19 dokter (55,9\%) dari 34 dokter tidak tepat.

Uji statistik yang digunakan dalam analisis bivariabel adalah chi-squaredan Ratio Prevalence (RP) dengan tingkat kemaknaan $(\alpha=0,05)$ dengan Confidence Interval $(C l)=95 \%$. Adapun hubungan antara variabel bebas dengan variabel terikat (Tabel 4) :

Tabel 4.Hubungan antara pengetahuan dan sikap dokter tentang rekam medis dengan ketepatan koding diagnosis berdasarkan ICD di RSUD Arjawinangun Cirebon Tahun 2016

Ketepatan $\mathrm{p}$ value

$\begin{array}{ccccc}\text { Tepat } & & & \text { Fis } & \text { Chi } \\ & \text { Tidak } & \text { RP } & \text { her' } & - \\ & \text { Tepat } & & \text { sex } & \text { Squ } \\ & & & \text { act } & \text { are }\end{array}$

\begin{tabular}{cccccc}
\hline $\begin{array}{l}\text { Pengetahuan } \\
\text { n (\%) }\end{array}$ & & & & & \\
\hline Tinggi & 10 & 11 & 0,7 & 0,4 & 0,6 \\
& $(47,6 \%)$ & $(52,4 \%)$ & 28 & 35 & 01 \\
Rendah & 5 & 8 & & & \\
& $(38,5 \%)$ & $(61,5 \%)$ & & &
\end{tabular}

Sikap

$\mathrm{n}(\%)$

\begin{tabular}{lccccc}
\hline Baik & 10 & 7 & 0,1 & 0,0 & 0,0 \\
Kurang & $(58,8 \%)$ & $(41,2 \%)$ & 66 & 83 & 84 \\
Baik & 5 & 12 & & & \\
& $(29,4 \%)$ & $(70,6 \%)$ & & & \\
\hline
\end{tabular}

Hasil analisis seperti terlihat pada Tabel 4 menunjukkan bahwa antara pengetahuan dengan ketepatan koding diagnosis berdasarkan ICD tidak berhubungan secara signifikan dengan $p$ value $=0,601$ dan nilai $R P=1$. Hal ini berarti bahwa hipotesis ada hubungan antara pengetahuan dengan ketepatan koding diagnosis ditolak dan antara sikap dengan ketepatan koding diagnosis berdasarkan ICD tidak berhubungan secara signifikan dengan $\mathrm{p}$ value $=0,084$ dan nilai $\mathrm{RP}=$ 0,18 . Hal ini berarti bahwa hipotesis ada hubungan antara sikap dengan ketepatan koding diagnosis ditolak.

\section{PEMBAHASAN}

Ketepatan dan ketidaktepatan kode diagnosis berdasarkan ICD di RSUD Arjawinangun Kabupaten Cirebon

Hasil analisis pada tabel 3 menunjukkan bahwa distribusi dokter dengan ketepatan kode diagnosis berdasarkan ICD di RSUD Arjawinangun Kabupaten Cirebon didapat sebanyak 19 dokter (55,9\%) dari 34 dokter tidak tepat. Hasil analisis univariat pada tabel 2 menunjukkan bahwa kode diagnosis pada dokumen rekam medis di Rawat Jalan RSUD Arjawinangun Kabupaten Cirebon yang akurat atau tepat sebanyak 1067 (88,9\%) dan yang tidak akurat atau tepat sebanyak $133(11,1 \%)$ dari 1200 dokumen rekam medis (DRM). Hal ini sejalan dengan hasil penelitian yang dilakukkan oleh Rahayu, et. all. (2009) bahwa kode diagnosis utama pada dokumen rekam medis bangsal Karmel RS. Mardi Rahayu Kudus pada Bulan Desember 2009 yang akurat sebanyak 103 DRM $(69,59 \%)$ dan yang tidak akurat sebanyak 45 DRM (30,41\%). Ketidaktepatan kode diagnosis masih terjadi di RSUD Arjawinangun Kabupaten Cirebon (11,1\%).

Salah satu faktor yang menyebabkan ketidakakuratan kode diagnosis adalah tidak adanya prosedur tetap yang mengatur mengenai tata cara penulisan diagnosis dan penentuan kode diagnosis. Hal ini sesuai dengan hasil penelitian Rismawan (2012), bahwa persentase ketidaktepatan kode diagnosis berdasarkan ICD-10 di Puskesmas Gondokusuman II Yogyakarta mencapai $66,67 \%$.

Faktor-faktor yang menyebabkan ketidak akuratan kode diagnosis adalah tidak adanya prosedur tetap yang mengatur mengenai tata cara penulisan diagnosis dan penentuan kode diagnosis, tidak adanya petugas khusus pengkodean yang mempunyai latar belakang pendidikan rekam medis dalam pelaksanaan pengkodean, sistem informasi kesehatan untuk kode diagnosis yang ada pada komputer di Puskesmas Gondokusuman II Yogyakarta kurang lengkap dan kurang spesifik. 
Menurut Naga (2003), pengkodean atau kodefikasi adalah salah satu cara yang mampu menyeragamkan pendataan individual penyakit pasien demi kepastian akurasi, presisi, ketepatan waktu dan tindakan yang akan dijadikan input suatu sistem informasi manajemen yang dikembangkan. Kualitas data dan informasi pelayanan kesehatan membutuhkan keakuratan dan kekonsistenan data yang dikode. Kualitas dari data yang dikode sangat penting bagi fasilitas pelayanan kesehatan. Keakuratan pengkodean sangat penting dalam manajemen data, pembayaran dan lainnya. Kualitas data pengkodean harus dapat dipertanggungjawabkan berarti hasil pengkodean rekam medis oleh beberapa petugas pengkodean akan menghasilkan kode yang sama, valid berarti hasil pengkodean harus mencerminkan keadaan pasien dan tindakan atau prosedur yang diterima pasien, lengkap berarti hasil pengkodean harus mencerminkan semua diagnosis dan semua prosedur yang diterima oleh pasien dan tepat waktu berarti hasil pengkodean yang dilakukan dengan tepat waktu, sehingga dapat digunakan untuk pengambilan keputusan rekam medis (Skurka, 2003).

\section{Hubungan antara pengetahuan dokter tentang rekam medis dengan ketepatan koding diagnosis berdasarkan ICD di RSUD Arjawinangun Kabupaten Cirebon}

Analisis dengan tabulasi silang pada Tabel 3 menunjukkan bahwa pengetahuan dokter tentang rekam medis yang tinggi, ketepatan koding diagnosis berdasarkan ICD cenderung tepat $(47,6 \%)$, sedangkan pengetahuan dokter tentang rekam medis yang rendah, cenderung ketepatan koding berdasarkan ICD tidak tepat $(61,5 \%)$, dan hubungan keduanya memiliki $p>0,05$ dan nilai $R P=0,728$. Hal ini berarti pengetahuan dokter tentang rekam medis yang tinggi kemungkinan ketepatan koding diagnosis berdasarkan ICD 0,728 kali dibandingkan dengan pengetahuan dokter yang rendah. Hubungan ini berarti bahwa semakin tinggi pengetahuan dokter tentang rekam medis, semakin tinggi pula ketepatan koding diagnosisnya. Demikian pula sebaliknya, semakin rendah pengetahuan dokter tentang rekam medis, maka semakin rendah pula ketepatan koding diagnosisnya.

Berdasarkan hasil analisis univariabel diketahui bahwa dokter yang mempunyai pengetahuan rendah sebanyak 13 orang $(38,2 \%)$ dari 34 responden. Pihak manajemen rumah sakit masih perlu melakukan upaya-upaya peningkatan pengetahuan, misalnya dengan pelatihanpelatihan.

Panggabean (2002) berpendapat bahwa pelatihan dapat diartikan sebagai suatu cara yang digunakan untuk memberikan atau meningkatkan keterampilan dan pengetahuan yang dibutuhkan dalam melaksanakan pekerjaannya. Penelitian yang dilakukan oleh Dieleman, et all. (2003) menjelaskan bahwa untuk meningkatkan pengetahuan petugas kesehatan tidaklah seperti pendidikan atau pelatihan, bisa juga dengan cara-cara lain seperti pertemuan-pertemuan yang berkaitan dengan penigkatan pengetahuan rekam medis.

Hubungan antara sikap dokter tentang rekam medis dengan ketepatan koding diagnosis berdasarkan ICD di RSUD Arjawinangun Kabupaten Cirebon

Analisis dengan tabulasi silang pada Tabel 3 menunjukkan bahwa sikap dokter yang baik terhadap rekam medis, ketepatan koding diagnosis berdasarkan ICD cenderung tepat $(58,8 \%)$, sedangkan sikap dokter yang kurang baik terhadap rekam medis, cenderung ketepatan koding diagnosis berdasarkan ICD cenderung tepat $(29,4 \%)$, dan hubungan keduanya memiliki nilai $p>0,05$ dan nilai $\mathrm{RP}=$ 0,166 . Hal ini berarti bahwa sikap dokter yang baik kemungkinan ketepatan koding diagnosis 0,166 kali dibandingkan dengan sikap dokter yang kurangbaik. Hubungan ini berarti bahwa semakin baik sikap dokter, semakin tepat koding diagnosisnya. Demikian pula sebaliknya, semakin kurang baik sikap dokter, semakin rendah ketepatan koding diagnosisnya.

\section{SIMPULAN DAN SARAN}


Berdasarkan pada hasil penelitian dan pembahasan yang telah diuraikan pada BAB IV, maka dapat disimpulkan sebagai berikut :

1. Pengetahuan dokter tentang rekam medis di RSUD Arjawinangun Kabupaten Cirebon yang baik sebanyak $61,8 \%$.

2. Sikap dokter tentang rekam medis di RSUD Arjawinangun Kabupaten Cirebon baik dan kurang baik mempunyai persentase yang sama (50\%).

3. Kesesuaian koding diagnosis berdasarkan ICD-10 di RSUD Arjawinangun Kabupaten Cirebon yang sesuai sebanyak $88,9 \%$.

4. Tidak ada hubungan yang signifikan antara pengetahuan dokter tentang rekam medis dengan kesesuaian koding diagnosis berdasarkan ICD-10 di RSUD Arjawinangun Kabupaten Cirebon.

5. Tidak ada hubungan yang signifikan antara sikap dokter tentang rekam medis dengan kesesuaian koding diagnosis berdasarkan ICD-10 di RSUD Arjawinangun Kabupaten Cirebon.

Berdasarkan analisis hasil penelitian, pembahasan dan kesimpulan serta mengacu pada manfaat penelitian, maka saran yang dapat diberikan antara lain :

1. RSUD Arjawinangun Kabupaten Cirebon :

a. Perlu merencanakan pelatihan, khususnya pelatihan rekam medis, sehingga pengetahuan dokter tentang rekam medis akan meningkat.

b. Perlu memperkuat pemahaman dan sikap dokter terhadap akurasi koding diagnosis berdasarkan ICD10 dengan mekanisme reward dan punishment yang jelas.

c. Perlu penguatan dengan SOP tentang tata cara penulisan diagnosis dan penentuan kode diagnosis.

2. Peneliti lain selanjutnya, agar memperhatikan faktor-faktor lain yang dapat mempengaruhi ketepatan koding diagnosis. Misalnya kebijakan manajemen rumah sakit, tenaga koder dan sarana dan prasarana rumah sakit.

\section{DAFTAR PUSTAKA}

1. Ardika., Ryco Giftan. Hubungan Antara Pengetahuan Perawat Tentang Rekam Medis dengan Kelengkapan Pengisian Catatan Keperawatan. Program Pendidikan Sarjana Kedokteran Fakultas Kedokteran Universitas Diponogoro;2012.

2. Depkes. RI,. Pedoman Pengelolaan Rekam Medis Rumah Sakit Indonesia. Jakarta;2006.

3. Dieleman, M., Cuong, P.V., Anh, L.V., dan Martineau, T., IdentifyingFactorsforJobMotivatio nofRuralHealthWorkers in NorthViet Nam. Human Resources forHealth. Vol. 1. No. 10;2003.

4. Hatta, Gemala R. Pedoman Manajemen Informasi Kesehatan di Sarana Pelayanan Kesehatan. Jakarta: Universitas Indonesia;2008.

5. Hatta, Gemala R. Pedoman Manajemen Informasi Kesehatan di Sarana Pelayanan Kesehatan revisi 2. Jakarta: Penerbit Universitas Indonesia (UI-Press); 2013.

6. Keputusan Menteri Kesehatan Republik Indonesia Nomor: 377/MENKES/SK/III/2007

Tentang Standar Profesi Perekam Medis.

7. Konsil Kedokteran Indonesia. Standar Kompetensi Dokter Indonesia. Jakarta;2012.

8. Maiga MN., Viva, Ansyon., Anis, Hariyanto., Tuti. Peran Pengetahuan dan Sikap Dokter dalam Ketepatan Koding Diagnosis berdasar ICD 10, 
Program Magister Manajemen Rumah sakit Fakultas Kedokteran Universitas Brawijaya, Malang;2014.

9. Manangka, F., Klasifikasi Statistik International Tentang Penyakit dan Masalah Kesehatan ( ICD- 10 ). Surabaya;1998, 